\title{
DYNAMOMETER TESTS OF AUTOMOBILE TIRES.
}

\author{
By W. L. Holt and P. L. Wormeley.
}

ABSTRACT.

This paper relates to a continuation of the work described in Technologic Paper No. 2I3, Power Losses in Automobile Tires. Power-loss tests have been made on a large number of tires, and the comparative results are shown for the $3^{T / 2}, 4$, and 5 inch sizes, both cord and fabric. An analysis is made of the effect of the different parts of the tire on the power loss, which shows that the carcass is responsible for the greater part of the loss. It is pointed out, and some examples are given showing, how dynamometer tests may be used as a help in studying the details of tire design.

\section{CONTENTS.}

Page.

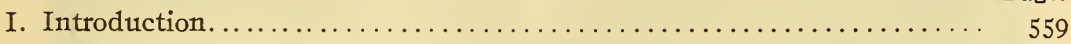

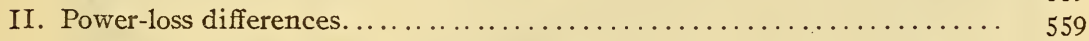

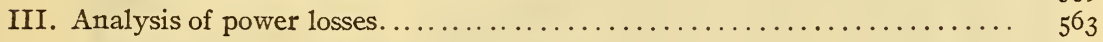

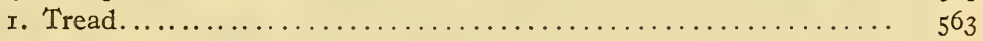

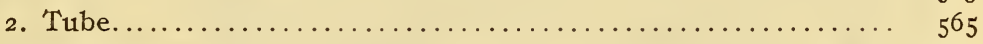

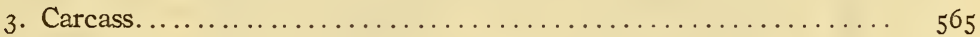

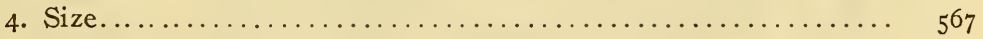

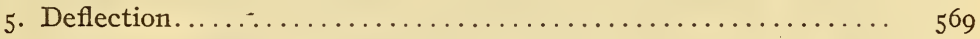

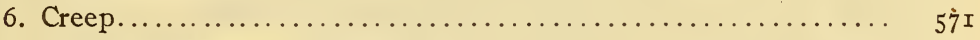

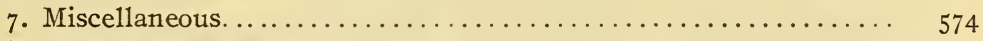

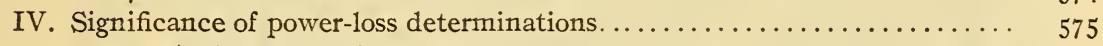

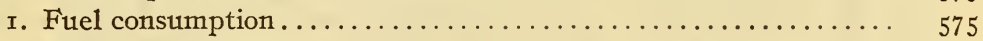

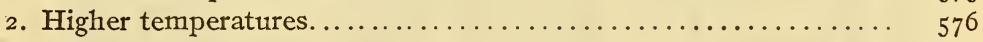

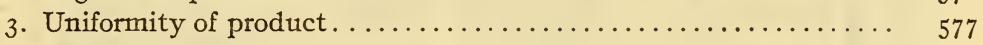

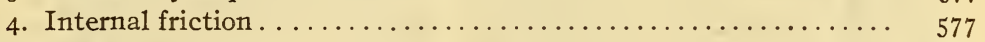

V. Conclusions. ..................................... $57^{8}$

\section{INTRODUCTION.}

In Technologic Paper No. 213, a description was given of the method of determining power losses in tires using electrical absorbtion dynamometers. General conclusions were drawn as to the effect on power loss of the different factors which enter into the operation of tires. A continuation of this work has shown that there are very marked differences in tires. An effort has been made to analyze these differences and bring out their significance.

\section{POWER-LOSS DIFFERENCES.}

With the many variables which enter into the operation of tires there are numerous ways in which comparisons can be made. One method of comparison is power loss versus air pressure, as 
shown in Figures 2, 3, and 4. All the data are based on a constant speed, no tractive effort, and a normal axle load-the air pressure being varied and corresponding power losses noted. The results given represent tests made on 72 different tires manufactured by 35 different companies. They were chosen at random from both small and large manufacturers, and are considered to be representative of average tires. Figure 2 shows comparisons of $30 \times 3 \frac{1}{2}$ tires; Figure 3, 4-inch tires, either $32 \times 4$ or $33 \times 4$; and Figure $4,35 \times 5$ tires.

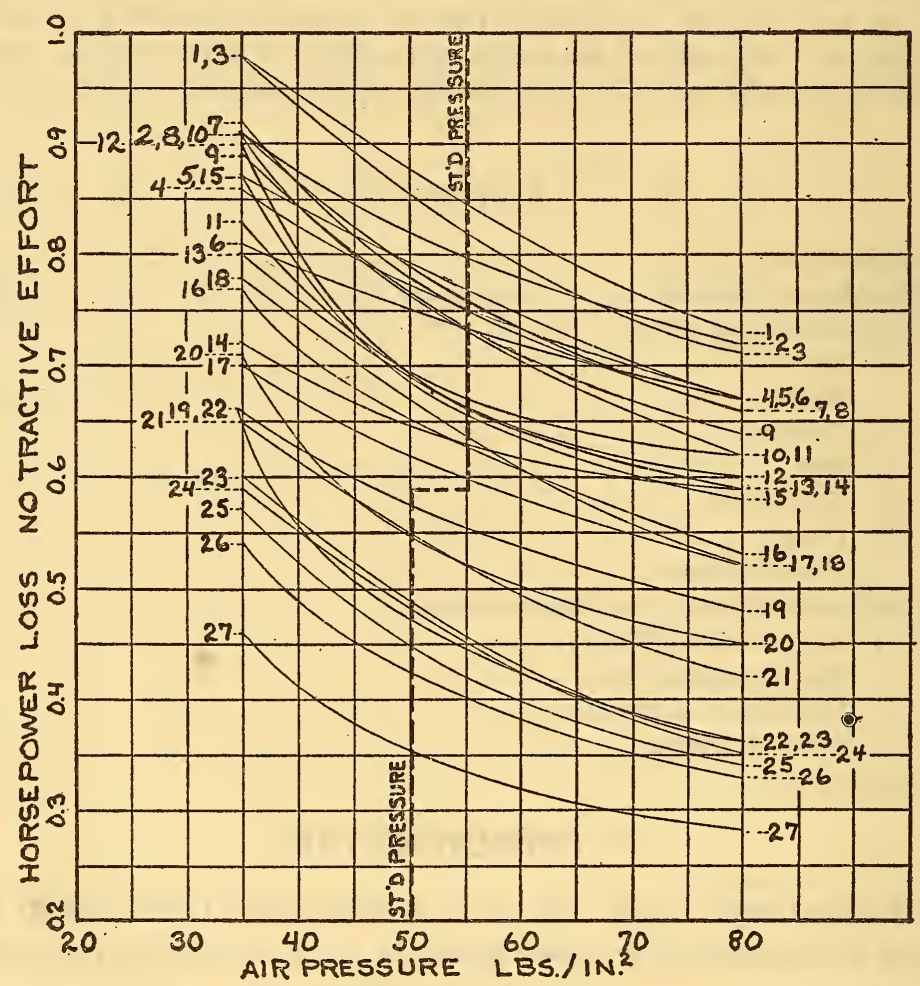

FIG. 2.-Comparison of $30 \times 3^{1 / 2}$ clincher tires.

Nos. I to $I 8$, fabric; Nos. I9 to 27 , cord; speed, $25 \mathrm{mph}$; axle load, 625 pounds.

Aside from two distinct divisions into which cord and fabric tires fall, it will be noted that there is quite a large variation in different makes of tires of the same class. From a study of these curves the following conclusions may be drawn. (These are based on air pressures, as recommended by the Society of Automotive Engineers.)

(a) The average loss in $30 \times 3 \frac{1}{2}$ fabric tires is $0.7 \mathrm{I}$ horsepower; in cord tires, 0.48 horsepower. 


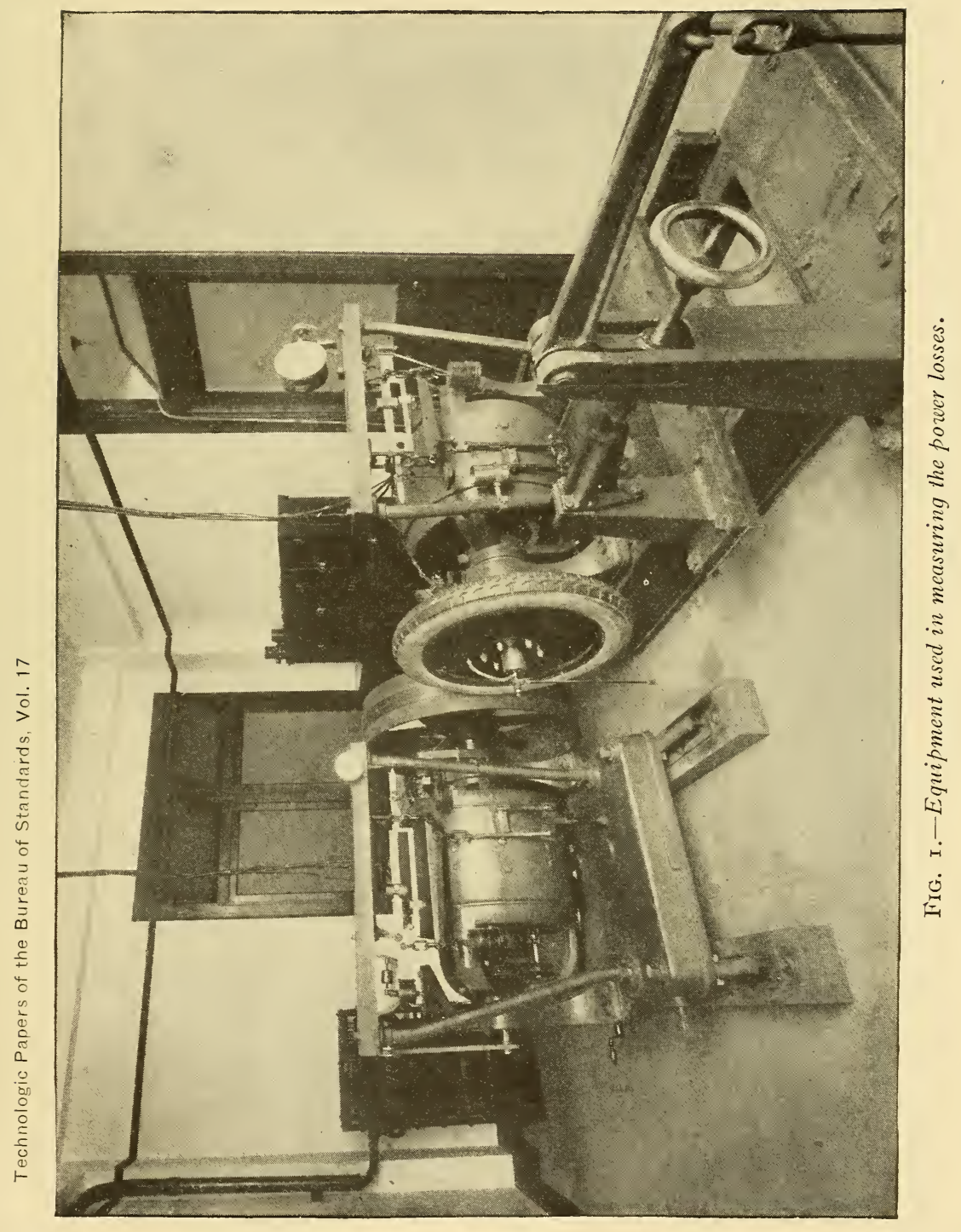



(b) The average loss in 4 -inch fabric tires is 0.94 horsepower; in cord tires, 0.67 horsepower.

(c) As an average, the loss in cord tires is approximately 70 per cent of that in fabrics.

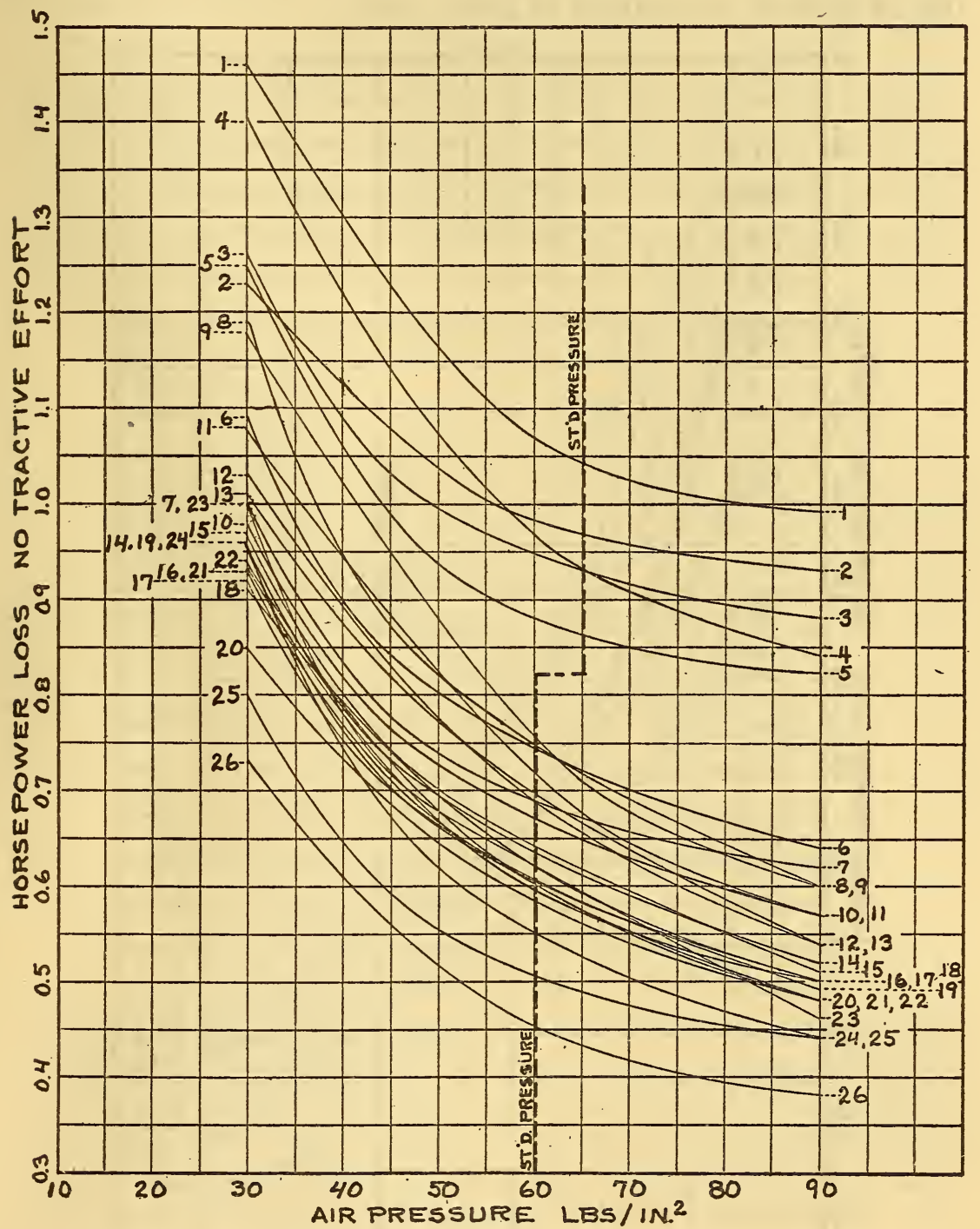

FIG. 3.-Comparison of 4-inch tires.

Nos. I to 5 , fabric; Nos. 6 to 26 , cord; speed, $25 \mathrm{mph}$; axle load, 885 pounds.

(d) Extreme cases, between the highest fabrics and the lowest cords, show the cord with only 40 per cent of the loss found in the fabric. 
(e) Considering only the cord tires, the lowest loss for each size of tire is about 60 per cent of that of the highest.

$(f)$ In general, the curves, whether for fabrics or cord, have the same trend. Individual tires show some differences in the rate of increase or decrease of power loss.

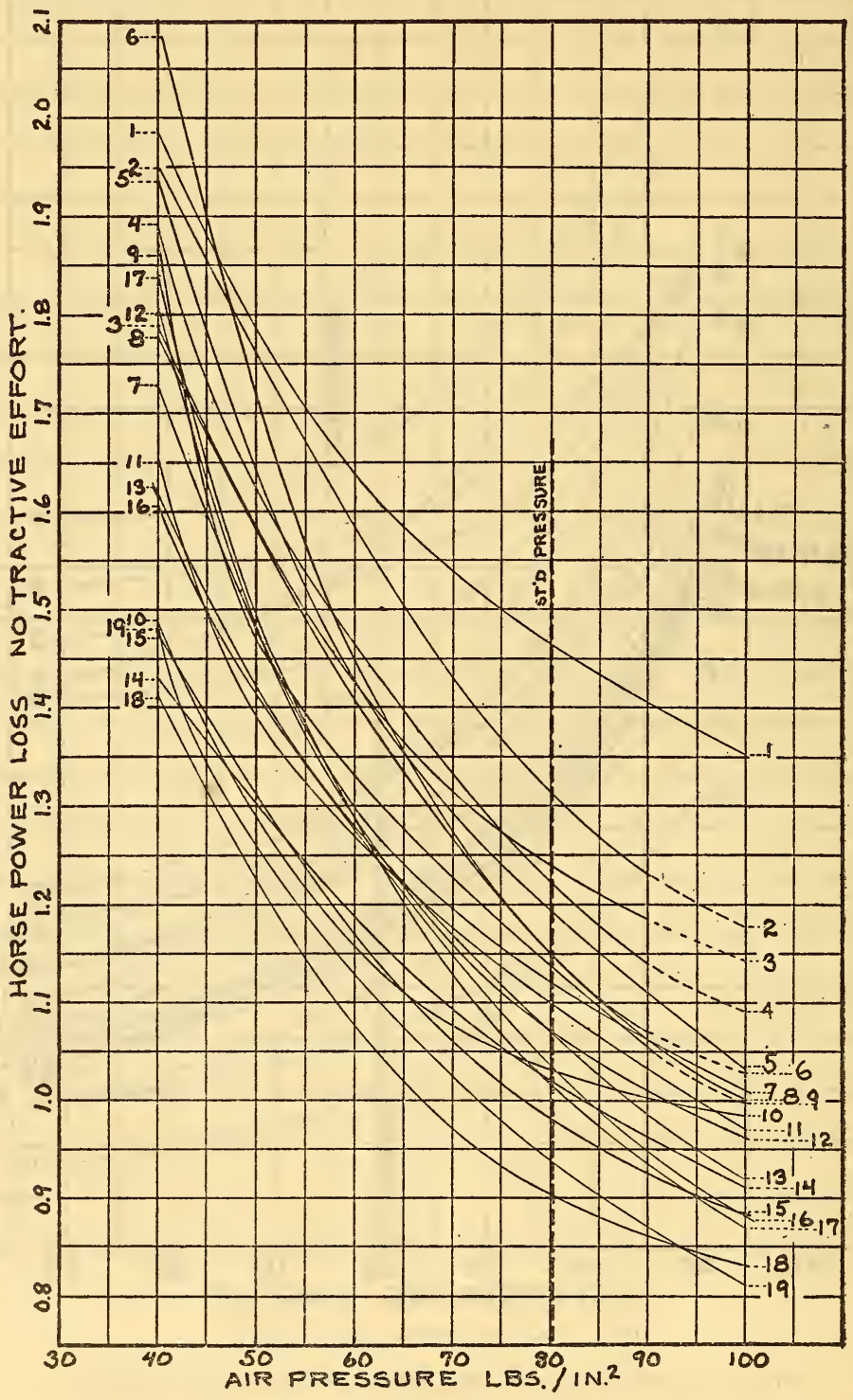

FIG. 4.-Comparison of $35 \times 5$ cord tires

Speed, $25 \mathrm{mph}$; axle load, $\mathrm{r}, 650$ pounds

The magnitude of these differences suggests that an analysis of their causes and effects should be of value in the design and construction of tires. 


\section{ANALYSIS OF POWER LOSSES.}

\section{TREAD.}

One of the most frequent questions asked when speaking of the power losses in tires is: "How does the tread design affect these losses?" It seems reasonable to expect that a tire which has a ribbed or smooth tread will offer less resistance to rolling and show a lower power loss than one with an irregular or "bumpy" tread. However, in making tests on a large number of tires it has been found impossible to predict even approximately the comparative power losses from the character of the treads. This made it appear that the tread was not the most important factor.

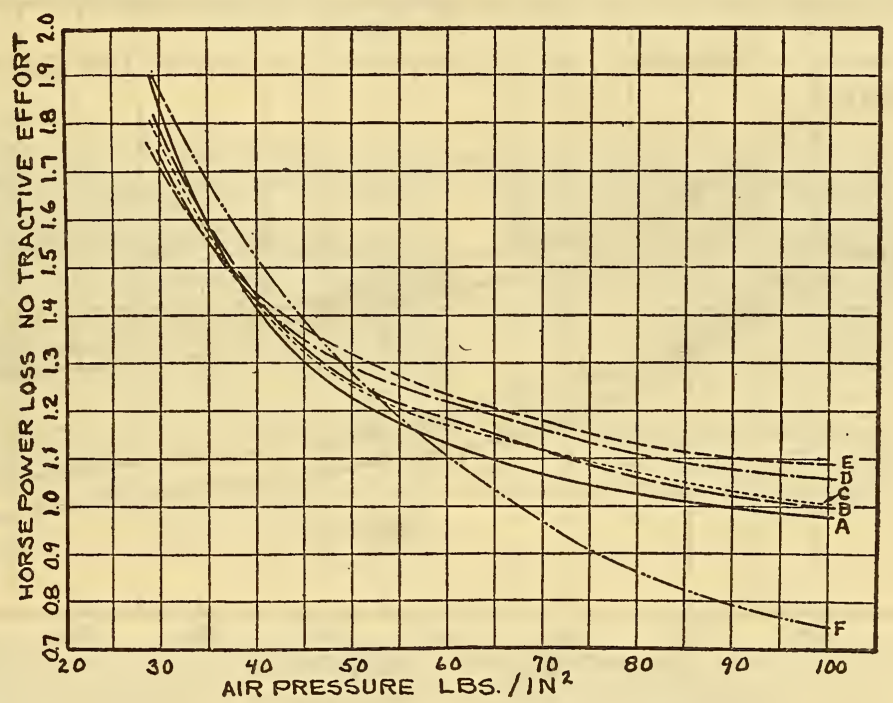

Fig. 5.-Effect of alterations in tread on power loss.

$35 \times_{5}$ cord tire; speed, $25 \mathrm{mph}$; axle load, , 650 pounds.

In order to determine the effect of different treads, a test was run as shown in Figures 5 and 6 . In the first test a regular $35 \times 5$ ribtread tire was used. The tread was then altered, successively, as shown in Figure 6 (A, B, C, etc:), and the tires retested after each change, the results of which are shown in Figure 5 (A, B, C, etc.). In $\mathrm{F}$ the tread was entirely removed.

Under a normal air pressure of 80 pounds it will be noted that the power loss increased with each cut from $\mathrm{A}$ to $\mathrm{E}$-the greatest difference occurring between $\mathrm{C}$ and $\mathrm{D}$, during which time the central continuous bar was cut. Tests $\mathrm{A}$ and $\mathrm{E}$ probably represent extremes of treads with respect to irregularity, and it will be noted that the increase in power loss between these extremes is 
about I I per cent. With the tread entirely removed the decrease is about I5 per cent. Under low air pressures the effect of the alterations in the tread is much less marked; in fact, under certain conditions it is entirely lost.

In order to determine the efiect of treads which have cavities in them forming so-called "vacuum cups," tests were run as shown in Figure 7. Two tires were used-a fabric and a cordand a run made on each; first with the drum dry and second, when the drum was kept wet by a continuous stream of water. The "cups" were then cut in such a way as to relieve any partial vacuum which might be formed, and the tire retested. It will

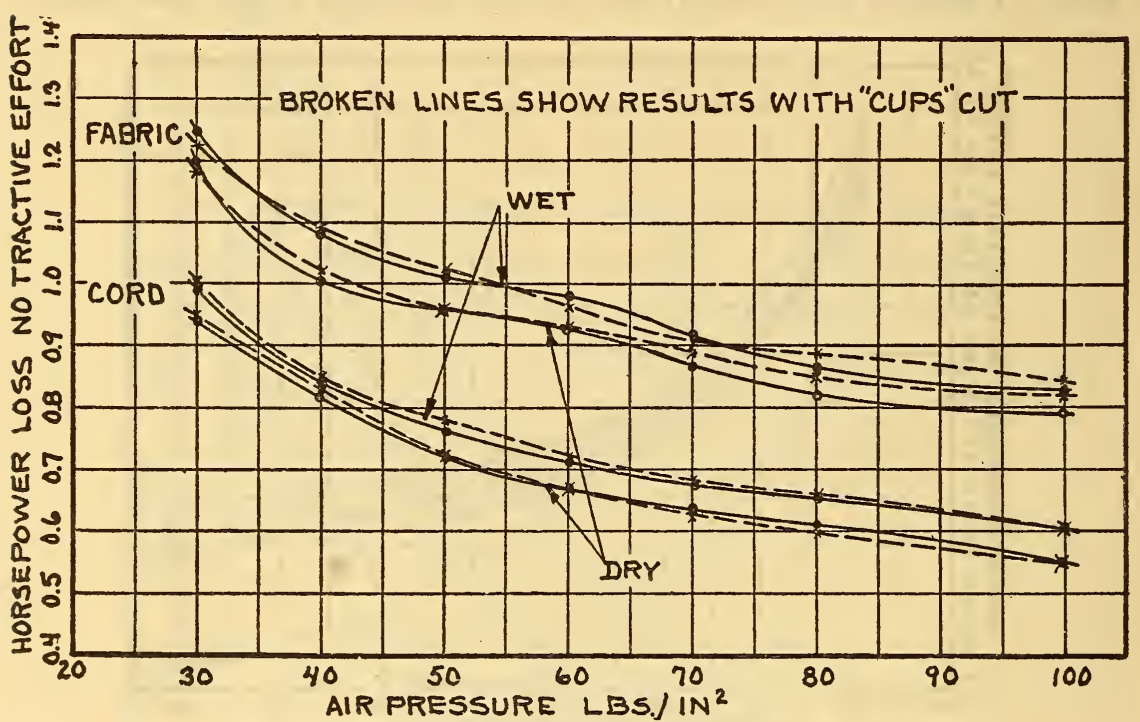

FIG. 7.-Power losses in "vacuum cup" tires.

Two $33 \times_{4}$ tires; speed, $25 \mathrm{mph}$; axle load, 885 pounds.

be noted that the effect of cutting the cups was negligible. In one case under high air pressures there was even apparently a slight increase in power loss, due to cutting the "cups," which is entirely contrary to what would be expected.

The difference between the wet and dry tests may be attributed to two causes; first, the wet tire ran at a slightly lower temperature, which would tend to increase the power loss; second, there was a decrease in the "creep" with the wet drum, which would have a similar effect. (This property of tires will be discussed under "Creep," p. 57I.) From these results, it appears that the energy used in producing the popping noise which is noticeable when these tires run along a wet pavement is very small. These 


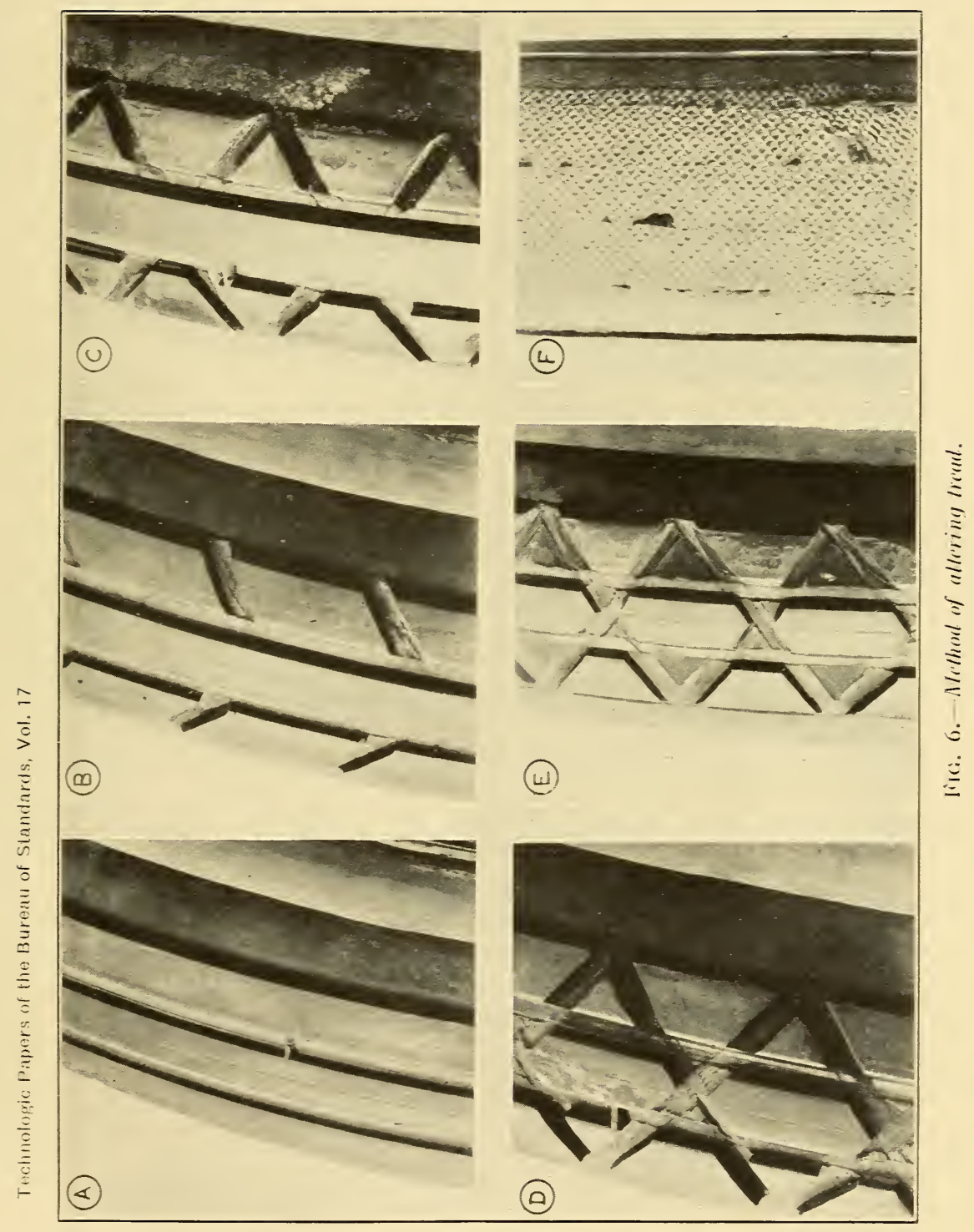


Technologic Papers of the Bureau of Standards, Vol. 17

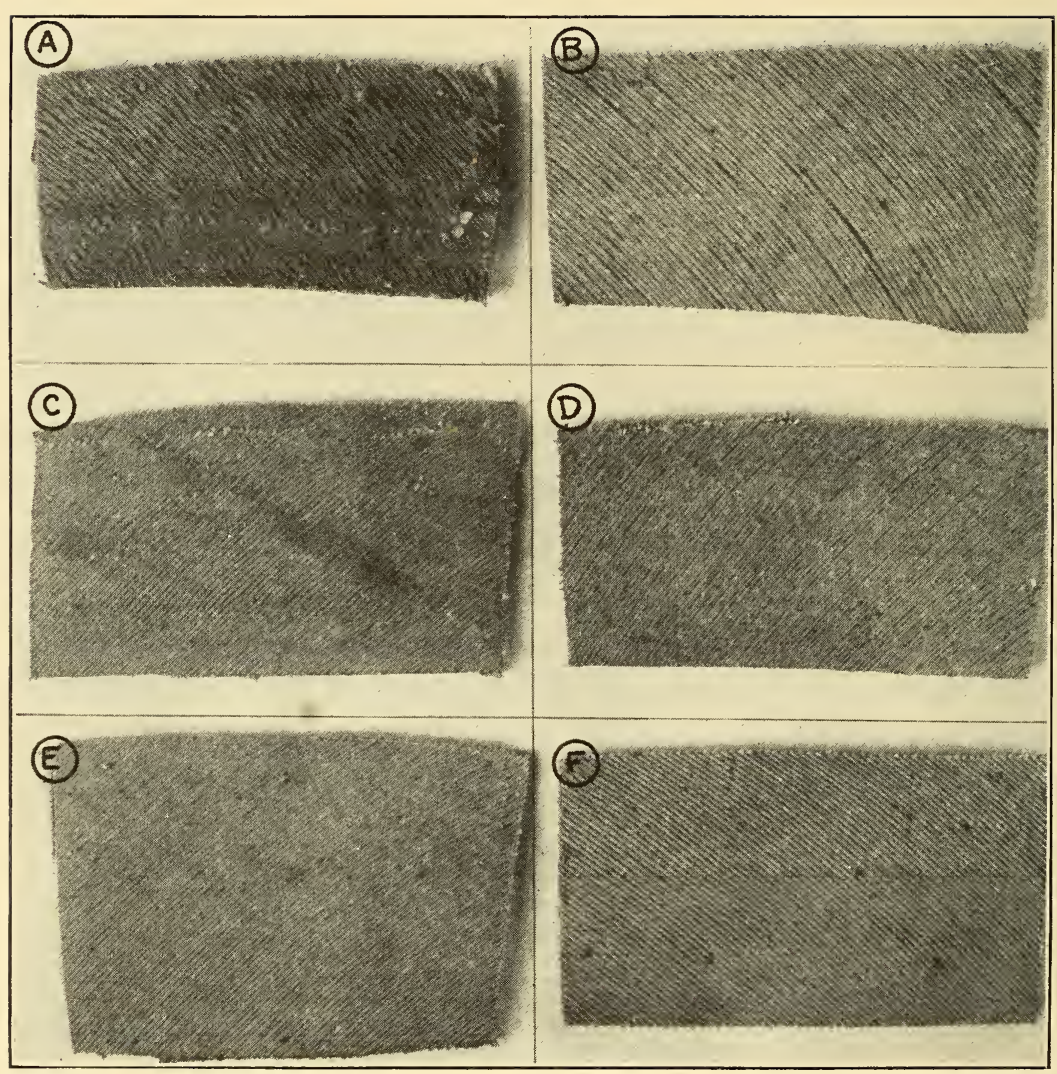

Fig. 8.-Lay'up of cords in tires. 
experiments, the results of which are confirmed by general observations, show that the loss in the tread represents only a small part of the total loss in the tire.

\section{TUBE.}

Inasmuch as the tread which is entirely rubber has a small effect on the power loss compared with the remainder of the tire, it would be expected that the tube, which is also entirely rubber and of much smaller volume, would have an even smaller effect. In order to check this conclusion four tubes were selected as follows:

(a) A $35 \times 5$ red tube, weight 4.3 pounds.

(b) A $35 \times 5$ red tube, weight 5.2 pounds.

(c) A $35 \times 5$ red tube, weight 5.2 pounds.

(d) A $35 \times 5$ heavy compression tube, weight $2 \mathrm{I} .2$ pounds.

Power-loss tests were run on a $35 \times 5$ tire under as nearly identical conditions as possible, using each tube. When the $(d)$ tube was used, a slightly higher power loss ( 2 to 3 per cent) was shown, but aside from this the results were essentially the same.

The test was then repeated, using in one case a red tube, and in another a gray tube in combination. with a so-called punctureproof shield. This shield consisted of an endless band of rubber which was placed between the tube and the tread portion of the casing. It was about 5 inches wide and one-half inch thick at the center, tapering to nothing at the edges. In both tests, using the combination of tube and shield, the results showed a power loss about 5 per cent higher than when using the tube alone. This increase was probably caused in large measure by the poor quality of the rubber compound in the shield. In order to obtain conclusive information as to just the effect of these special types of tubes and appliances more exhaustive tests would be required. However, the facts that tubes of different makes produce no appreciable effect on the power loss, and that a large increase in the amount of rubber in the tube, or used in connection with it, has no very great effect, confirm the conclusions that the losses due to tubes of the standard type are small.

\section{CARCASS.}

By the process of elimination, the greater part of the power loss must occur in the carcass of the tire. That such is the case is brought out by the difference in power losses in cord and fabric tires where practically the only difference is in the carcass con$53617^{\circ}-23-2$ 
struction. When run under the same conditions in all the tests to date we have not found a single cord tire whose power loss was as great as the lowest power loss found in any fabric tire of the same size. This is evident from Figures 2 and 3 .

It might be thought that the differences in cord or fabric tires are simply due to unusual features in the design. In some instances such is the case, but unusual features do not prove to be the only causes of these variations. For instance in Figure 2 tires Nos. I, 9, and I7 are 5-ply tires, the remainder are 4-ply. One of these 5-ply tires shows the highest loss, one the lowest, and the other about average. Tests were run on several makes of tires which were built with a smaller number of plies of heavy cord in place of the usual light cord. The power losses varied from unusually high to unusually low, apparently depending to a large extent on the cord construction and on whether or not the cords were well impregnated with rubber. It has been found that the amount of rubber between the different plies of the carcass has a very marked effect. Wherever this thickness is low the power loss is invariably high.

In an examination of the three tires of each size showing the lowest losses an unusually uniform lay-up of the cords was observed. When compared with a large number of other tires it was quite evident that from the standpoint of uniform construction there were none that equaled them. Figure 8 shows the lay-up of cords in several tires using sections cut from the carcasses. $\mathrm{E}$ and F were taken from the two tires showing the lowest power losses in Figures 2 and 3 . The others were taken from tires showing higher losses. A is a section of a tire in which the cords are extremely wavy. In such a tire the strain would probably be concentrated on one or two plies which would soon give out, and a blow-out result. The condition of the cords in B is much better, but it will be seen that they are not very evenly laid. In $\mathrm{C}$ there is just a slight wave in the cords, otherwise they are fairly uniform. D is a sample of cord construction which is probably a little better than the average, in fact, almost as uniform as E. The low power loss in $\mathrm{E}$ and $\mathrm{F}$ is not due to a lesser number of cords per inch as evidenced by the fact that both $\mathrm{B}$ and $\mathrm{F}$ have about 22 cords per inch while C, D, and E all have about 26 cords per inch. There is no question but that the uniformity of cord construction, which means uniform distribution of strain in tires $\mathrm{E}$ and $\mathrm{F}$ is a factor which makes them stand out far below the average in power loss. 
4. SIZE.

By this is meant the width of the cross section of the inflated tire measured parallel to the axis of the wheel. Considerable variation in size is found in different makes of tires of the same rated size as shown in Table $\mathrm{I}$.

TABLE 1.-Summary of the Cross Section of Various Tires.

\begin{tabular}{|c|c|c|c|c|c|}
\hline Description of tires. & $\begin{array}{l}30 \times 3^{1 / 2} \\
\text { fabric. }\end{array}$ & $\begin{array}{c}30 \times 3 \mathrm{~T} / 2 \\
\text { cord. }\end{array}$ & $\begin{array}{l}\text { 4-inch } \\
\text { fabric. }\end{array}$ & $\begin{array}{l}\text { 4-inch } \\
\text { cord. }\end{array}$ & $\begin{array}{l}\text { 5-inch } \\
\text { cord. }\end{array}$ \\
\hline 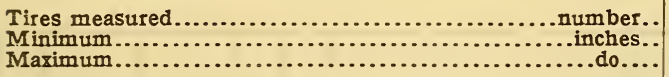 & $\begin{array}{r}18 \\
3.33 \\
3.61\end{array}$ & $\begin{array}{r}9 \\
3.36 \\
3.91\end{array}$ & $\begin{array}{r}5 \\
4.25 \\
4.68\end{array}$ & $\begin{array}{r}20 \\
4.27 \\
4.73\end{array}$ & $\begin{array}{r}19 \\
5.35 \\
5.94\end{array}$ \\
\hline 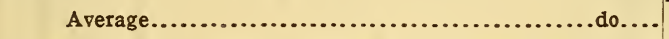 & 3.49 & 3.63 & 4.40 & 4.52 & 5.66 \\
\hline
\end{tabular}

In order to determine whether these variations in size account or power-loss differences some general observations were made as to the effect of size. This is conveniently done from values shown in Figures 2, 3, and 4, taking a wide range of sizes-from $3 \frac{1}{2}$ to 5 inches. As a basis of comparison, the standard pressures are taken for each size of tire and instead of expressing the absorption of energy as a horsepower at a certain speed, it has been calculated as the pounds rolling resistance per $\mathrm{I}, 000$ pounds axle load. The results are shown in Table 2.

TABLE 2.-Summary of the Rolling Resistance of Various Tires, in Lbs./1,000 Lbs., Axle Load.

\begin{tabular}{|c|c|c|c|c|c|}
\hline Description of tires. & $\begin{array}{l}30 \times 3 \mathrm{I} / 2 \\
\text { fabric. }\end{array}$ & $\begin{array}{c}30 \times 3 \pi / 2 \\
\text { cord. }\end{array}$ & $\begin{array}{l}\text { 4-inch } \\
\text { fabric. }\end{array}$ & $\begin{array}{l}\text { 4-inch } \\
\text { cord. }\end{array}$ & $\begin{array}{l}5 \text {-inch } \\
\text { cord. }\end{array}$ \\
\hline 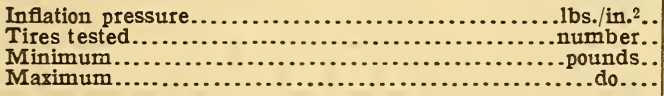 & $\begin{array}{r}55 \\
18 \\
14.4 \\
20.4\end{array}$ & \begin{tabular}{r|r}
50 \\
9 \\
8.7 \\
13.9
\end{tabular} & $\begin{array}{r}65 \\
5 \\
14.6 \\
17.6\end{array}$ & $\begin{array}{r}60 \\
20 \\
7.8 \\
12.5\end{array}$ & $\begin{array}{r}80 \\
19 \\
8.6 \\
13.4\end{array}$ \\
\hline 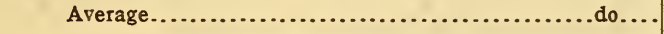 & 17.1 & 11.6 & 16.0 & 11.3 & 10.2 \\
\hline
\end{tabular}

It will be noted that the average rolling resistance per $\mathrm{I}, 000$ pounds for fabric tires runs from I 6 to I7.I pounds, and for cord tires from I0.2 to II.6 pounds. Based on the average figures, there is a small decrease in rolling resistance with increase in size; but taking into consideration the wide differences between minimum and maximum values, and the effect on these figures which a small change in air pressures would make, it is questionable whether this is of any significance. For instance, if 5 -inch cord results had been based on 75 pounds of air instead of 80 , the average rolling resistance would be I I.6 pounds instead of I0.2, or the same as the $3 \frac{1}{2}$-inch size. 
Accordingly, it seems fair to conclude that for tires from $3 \mathrm{~T} / 2$ to 5 inches in size, the rolling resistance per $\mathrm{I}, 000$ pounds axle load is independent of the size; which means that the relative performances of the different sizes of tires are the same.

It should be noted that these figures represent a rate of resistance rather than the actual resistance at the I,ooo-pound load. But since it has been found that the power loss, and hence the rolling resistance, is very nearly proportional to the axle load, the actual rolling resistance at any reasonable load for the tire in

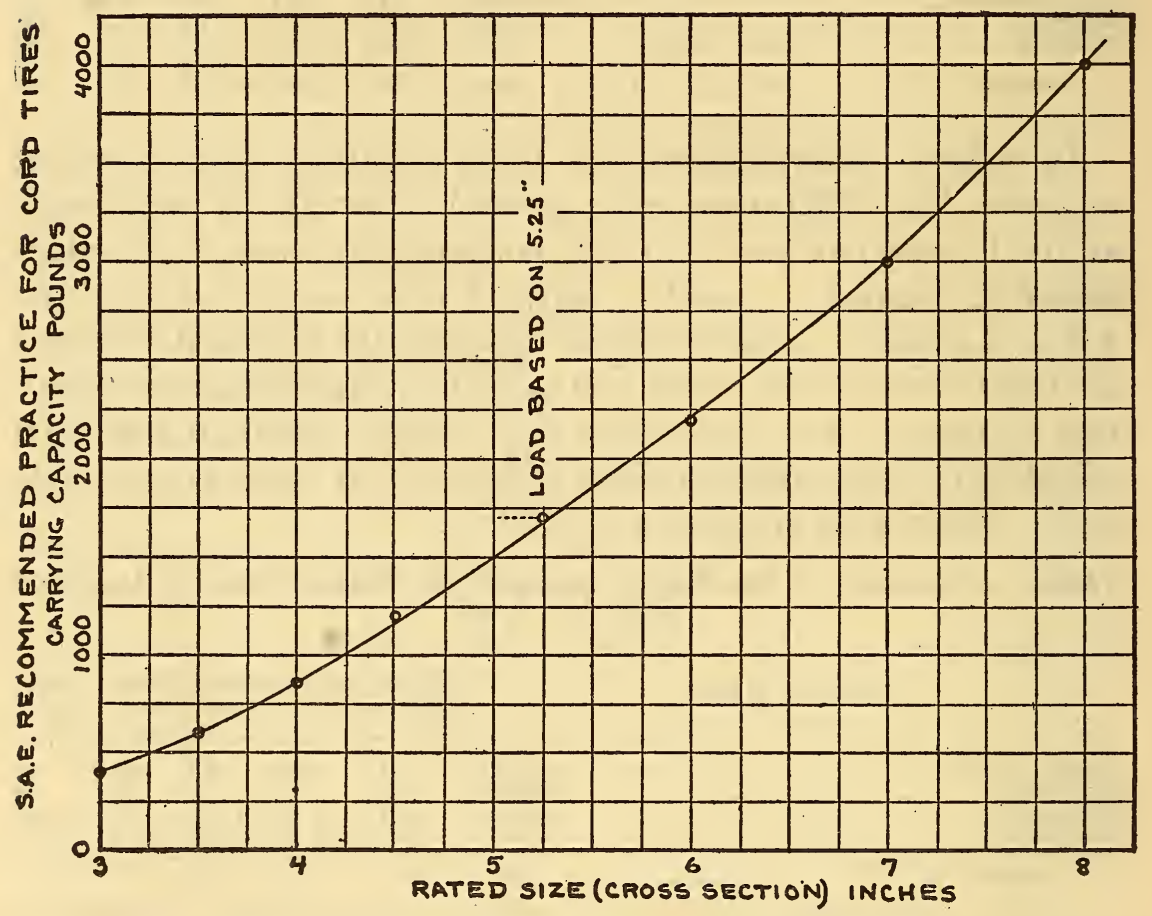

FIG. 9.-Rate of increase of carrying capacity with size.

question can be closely determined. Thus it can be seen that "oversize" tires, in general, would give no appreciable change in rolling resistance or power loss. As seen from Figures 2, 3, and 4 tires could be selected which would give either an increase or decrease in power loss. The advantage of the larger tires lies in greater tire life and increased carrying capacity.

By applying this reasoning to the variation in actual tire sizes as noted in Table I, it will be seen that the variations do not account for power-loss differences. In connection with these differences in size, it is interesting to note the curve shown in Figure 9. The values are simply the S. A. E. recommendations, and show 
the rate of increase in carrying capacity with increase in size. By applying this rate to differences in the actual size of tires of the same rated size, it will be seen that $0 . \mathrm{I}$ inch increase or decrease in cross section affects the carrying capacity by an amount varying from 40 to roo pounds. Taking into consideration the variations shown in Table $I$, it can be seen that if one car is equipped with four $30 \times 3 \frac{1}{2}$ minimum size fabric tires, and one with four $30 \times 3 \frac{1}{2}$ maximum size fabric tires the difference in carrying capacity would amount to about 500 pounds, or over 20 per cent of the

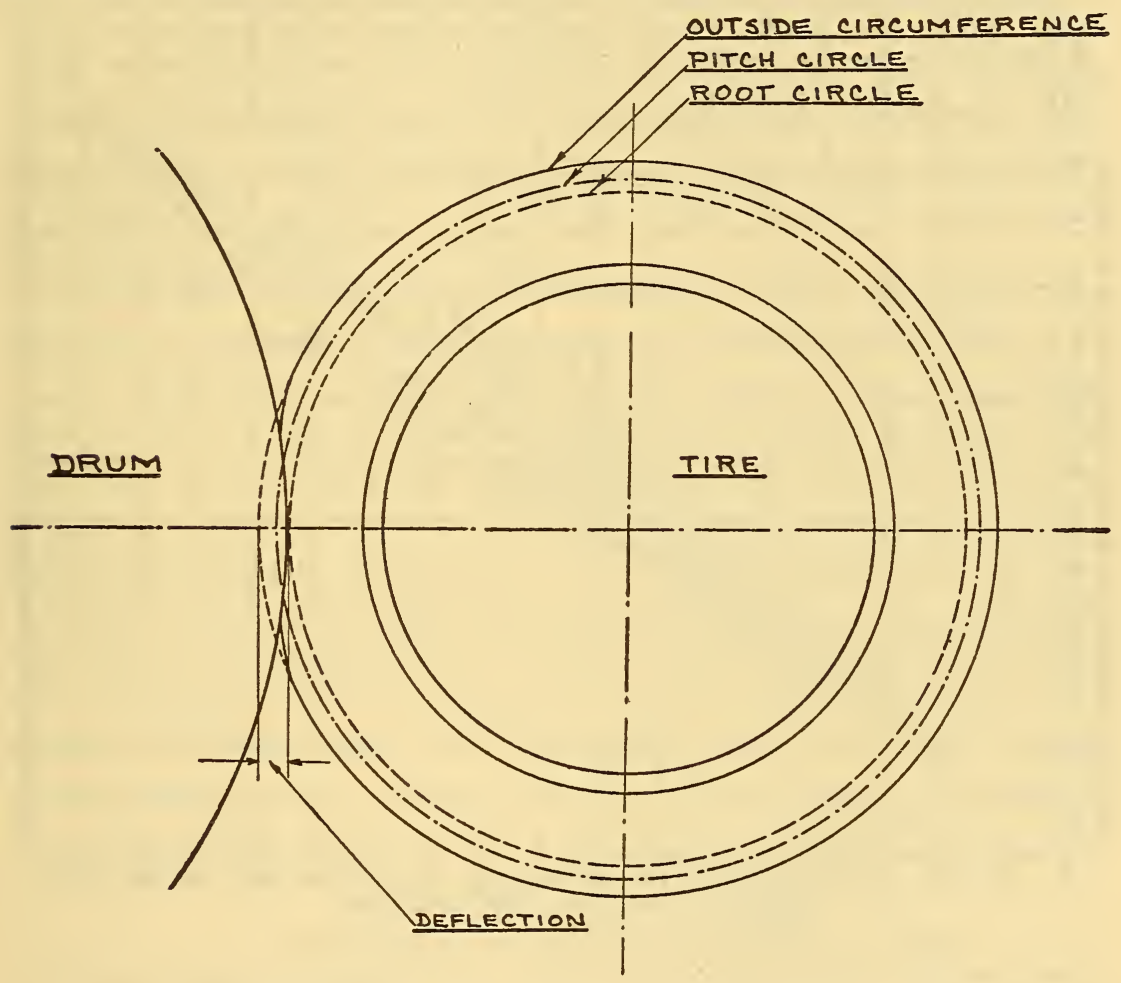

FIG. Io.-Diagram showing relative position of tire and drum on dynamometer.

total tire capacity. Of course, it is recognized that the carrying capacity of a tire is not an absolutely fixed quantity; but, nevertheless, the general rule that the carrying capacity increases with the size is based on sound reasoning as well as experience, and differences as noted above would certainly show up in the life of tires.

\section{DEFLECTION.}

By this is meant the decrease in the radial height of a tire (distance from the rim to the tread) due to the axle load. (See fig. Io.) - In general, a tire will deflect until the area in contact 
with the ground multiplied by the air pressure equals the axle load. It will vary somewhat with the construction and stiffness of the tire and the character of the tread, but the effect of these items is comparatively small unless the deflection is excessive. In tires of the same rated size a small difference in deflection is also due to the difference in actual size-the smaller the tire the greater being the per cent of deflection-but this has no vital effect on the power loss. In comparing the deflection of a tire with the power loss, two factors must be considered-the axle

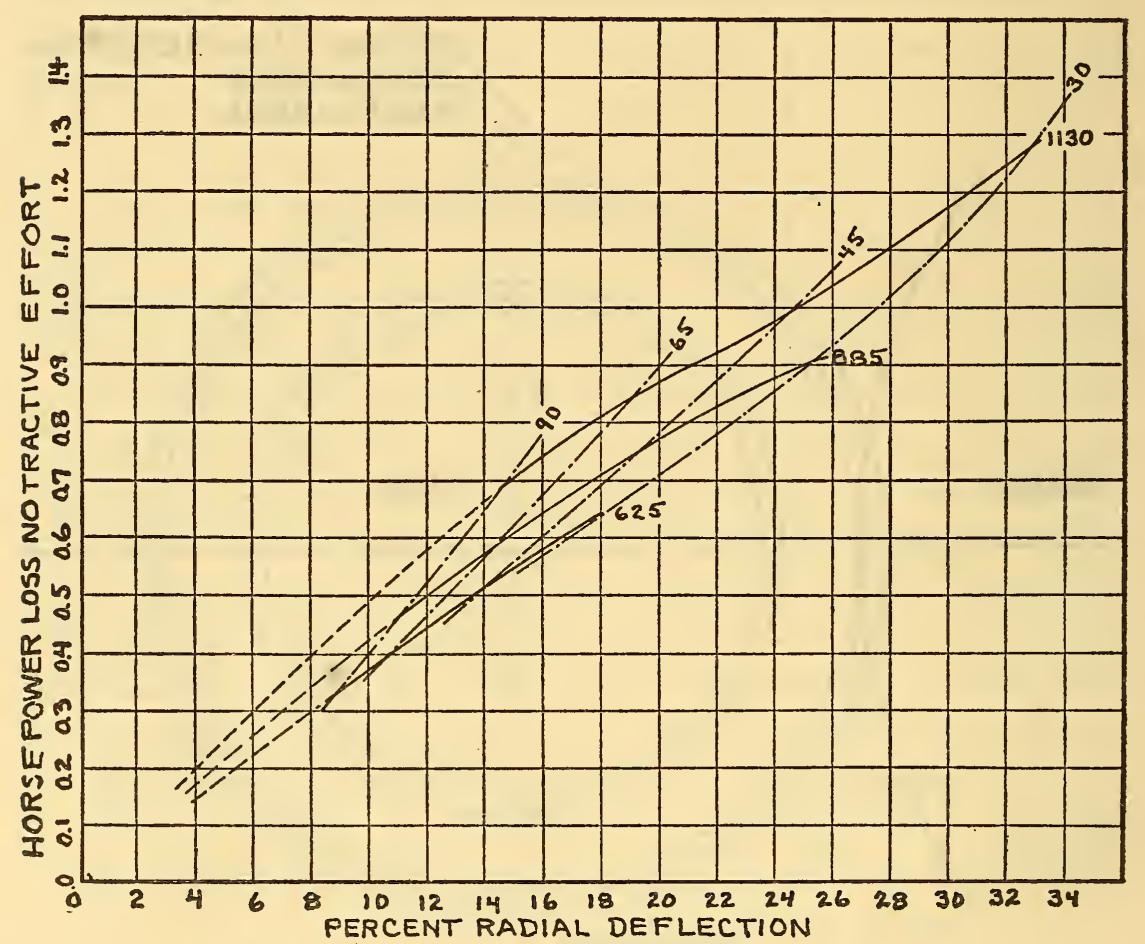

FIG. Ir.-Influence of radial deflection on power loss.

${ }_{32} \mathrm{X}_{4}$ cord tire; speed, $25 \mathrm{mph}$; axle load in pounds, $625,885, \mathrm{x}, \mathrm{x}_{3} \mathrm{O}$; air pressures in $\mathrm{lbs}$./in. ${ }^{2}, 30,45,65,90$.

load and the air pressure-inasmuch as the same deflection can be produced by different combinations of these two. Figure II is typical of the curves obtained when the power loss is plotted against the deflection. It will be noted that there is no direct relation. For a constant deflection the power loss increases with an increase in axle load.

These results show that the deflection or distortion of a tire in itself is not a measure of the power loss. Underinflation and overloading produce similar results as far as deformation of the tire is concerned. Overloading, however, produces the more severe action on a tire. 
6. CREEP.

The deflections referred to in the previous paragraph were measured while the tires were running on the dynamometer under the desired axle load and air pressure. In making these measurements and noting the effect on the distance traveled by the tire per revolution, some interesting results were observed. Referring to Figure Io, the root circle is one which is concentric with the tire axle and tangent to the road, or in this case to the drum. The circumference of the pitch circle represents the distance which the tire advances in one revolution under no tractive effort other than that necessary to overcome tire resistance. The diameter of this circle depends upon the construction of the tire and upon the conditions under which it is run. In some cases it is almost as large as the outside circumference of the tire and in some cases it is smaller than the root circle.

An attempt has been made to explain these variations and determine what effect they might have on the life of the tire.

The deflection of a tire when running causes a circumferential compression of the tread portion as it passes along the drum surface due to the difference in the length of the outside circumference and the root circle. If the tread is relatively noncompressible it will tend to pile up as it approaches the point of contact with the drum, but since an accumulated piling up is not possible the tread is compressed to a certain extent and passes between the tire proper and the drum at a slightly accelerated speed. It carries the drum with it at this speed, which in most cases is greater than that of the root circle. If the tread were entirely noncompressible, each revolution of the tire would produce a movement of the drum surface equal to the circumference of the tire, in which case the speed of the drum (the pitch circle) would be independent of the deflection; that is, the axle load and air pressure. This condition is very closely approximated in a certain type of tire which has a circumferential band embedded in the tread. However, the material in most tires is compressible to such a degree that the pitch diameter is affected by the conditions under which a tire is operated.

Thus, the tread portion of a tire produces what we have called a tread creep; that is, a gain in drum speed over that which would correspond to the root diameter.

At the same time that this creeping of the tread is taking place, the force necessary to turn the tire in overcoming the resistance 
to rolling produces a circumferential compression of the tire as a whole as it approaches the drum. On leaving the drum this compressed portion returns to its original length, thus producing a creep in the tire as a whole. This is analogous to the creep of a belt on a pulley. It is in the opposite direction from the tread creep and results in a loss in drum revolutions. This is referred to as the carcass creep. Thus it appears that there are two opposing factors tending to change the diameter of the pitch circle-the tread creep to increase it and the carcass creep to decrease it.

The foregoing applies to a tire run under no tractive effort. If there is a tractive effort, an opposing circumferential force is introduced which tends to further compress the tire as a whole, thus reducing the tread creep and increasing the carcass creep.

It is not a simple matter to separate this carcass and tread creep, but their sum is easily found. The root diameter is calculated from the formula

where

$$
D_{\mathrm{r}}=D_{\mathrm{o}}-2 k
$$

$D_{\mathrm{r}}=$ root diameter in inches,

$D_{\mathrm{o}}=$ outside diameter in inches,

$k=$ the deflection in inches.

When the tire is run under no tractive effort, the pitch diameter is calculated from the formula

where

$$
D_{\mathrm{p}}=\frac{R_{2}}{R_{1}} D_{\mathrm{d}}
$$

$D_{\mathrm{p}}=$ pitch diameter inches,

$D_{\mathrm{d}}=$ diameter of drum inches,

$R_{1}=$ revolutions per minute of tire,

$R_{2}=$ revolutions per minute of drum.

Creep $=\pi\left(D_{\mathrm{p}}-D_{\mathrm{r}}\right)$ inches per revolution of tire. This value may be either plus or minus.

Figure I2 shows the creep of eight different tires run under different axle loads and air pressures. A to $F$, inclusive, show the usual type of curves. $\mathrm{G}$ and $\mathrm{H}$ represent two tires that vary considerably, although they are of the usual construction. As to the effect of axle load and air pressures, it will be noted that in every case for a given air pressure the creep increases with the axle load, although the rate of increase is not at all constant. For a given axle load, the creep seems to follow no particular law, 
$35 \times 5$ CORD TIRE

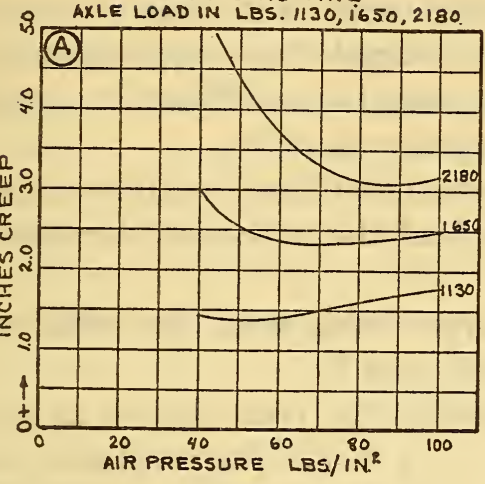

$33 \times 4$ FABRIC TIRE

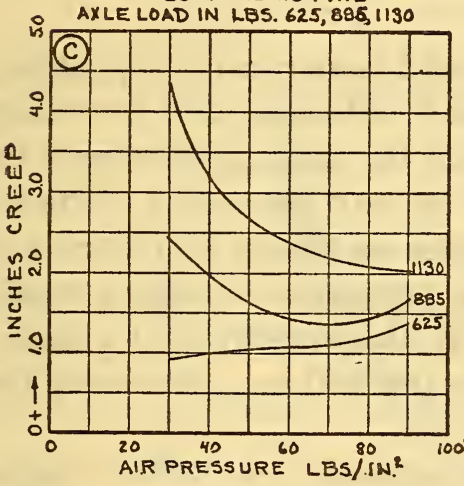

$32 \times 4$ CORD TIRE

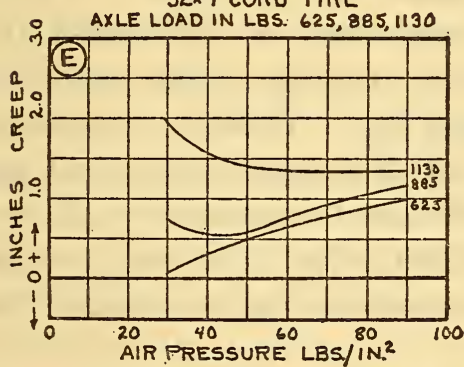

$33 \times 4$ CORD TIRE

AXLE LOAD IN EBS: $625,885,1130$

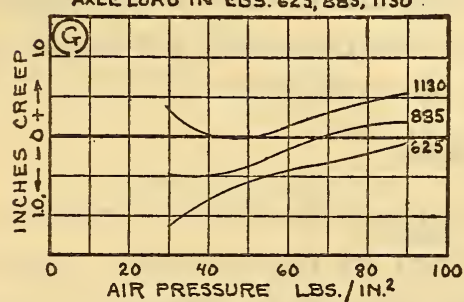

$37 \times 5$ CORD TIRE

- AXLE LOAD IN LBS. $1130,1650,2180$

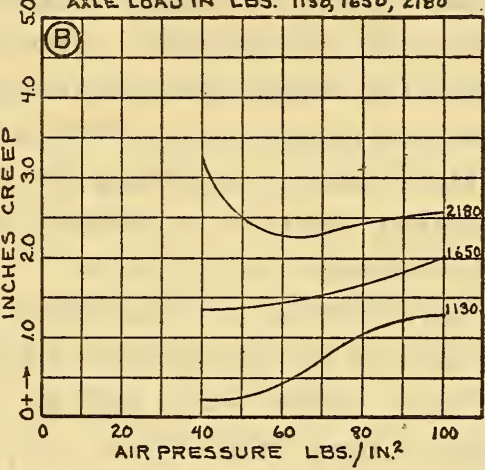

$33 \times 4$ FABRIC TIRE

AXLE LOAD IN LBS. $625,885,1130$

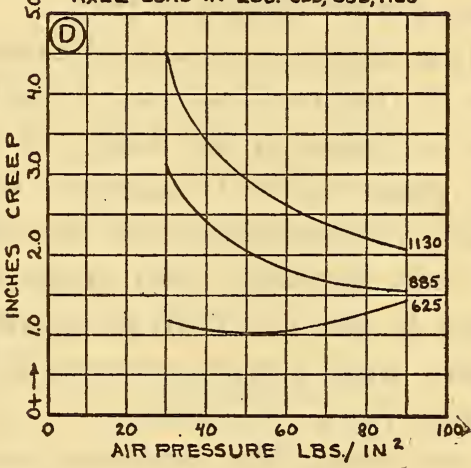

$33 \times 4$ CORD TIRE.

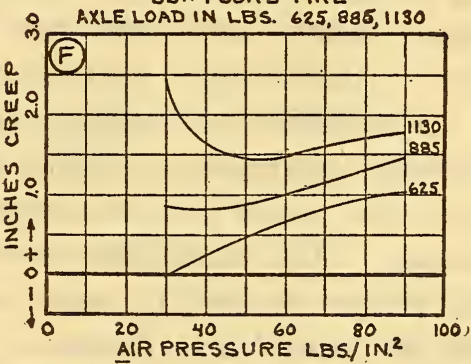

$33 \times 4$ CORD TIRE

AXLE LOAD IN LBS. 625,885, 1130

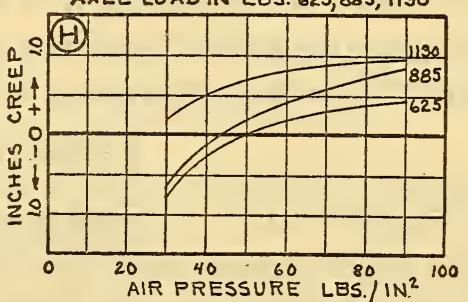

FIG. I2.-Influence of inflation pressure on creep for eight different tires shown as inches per tire revolution.

Speed, $25 \mathrm{mph}$; axle load, as shown; no tractive effort. 
in some cases increasing and in some cases decreasing with an increase in air pressure. This rather erratic behavior seems to uphold the theory that the resultant creep is a combination of the tread and carcass creep which are opposite in effect.

It will also be noted that the creep bears no direct relation to the deflection, since for a constant axle load the deflection decreases with increase in air pressure.

Fabric tires as a whole show a larger creep than cord tires, as will be seen by comparison of $\mathrm{C}, \mathrm{D}, \mathrm{E}$, and $\mathrm{F}$.

Under normal loads and air pressures the creep varies in the different tires from about -0.4 to +2.3 inches per revolution of tire. Under extreme conditions it varies from about $-\mathrm{I}$ to +5 inches per revolution of tire.

These figures represent adjustments which are continually taking place in the tread portion of the tire as it rolls along and provision must be made in the design of the tire for these adjustments to take place without excessive strain on any particular portion. Taking into consideration the difference as shown in Figure I2, it is not surprising that tread or ply separation develops much sooner in one tire than in another. It also appears that a satisfactory tread construction on a fabric tire will not necessarily be the best for a cord tire.

Considering any particular tire, it appears that other things being equal a decrease in creep increases the power loss. For instance, when tires were run wet and dry, as illustrated in Figure 7 , there was a decided decrease in creep in the wet test and a corresponding increase in power loss. While in this case the lower temperature during the wet test would also tend to increase the power loss, it was not sufficient to account for all the difference. The remainder was evidently due to a decrease in creep which resulted in more tire revolutions being required to cover the same linear distance.

While in comparing different tires there are many factors which affect the power loss, if cord and fabric tires are grouped separately the general tendency is for those tires with the smallest creep to show comparatively higher power losses.

\section{MISCELLANEOUS.}

In Section III, (I), it was pointed out how the effect of changes in the tread design could be determined by dynamometer tests. With each change in the tread there was also a change in the creep of the tire-comparatively small, but nevertheless dis- 
tinctly shown. It is obvious that a close correlation exists between these two factors. Figure I3 illustrates these creep changes-the letters corresponding to the designations in Figures 5 and 6 . It will be seen that the results, in general, bear out the conclusions reached in the preceding section, that a decrease in creep results in an increase in power loss.

Figure I 4 illustrates tests of four tires, all of the same make, but incorporating special features of design in such a way that comparisons can be made as to the effect of these features. For instance, $\mathrm{A}$ and $\mathrm{C}$ are identical, except for the number of cords per inch in the ply material; $\mathrm{B}$ and $\mathrm{C}$ are identical, except for the amount of rubber between the plies; $A$ and $D$ are identical, except

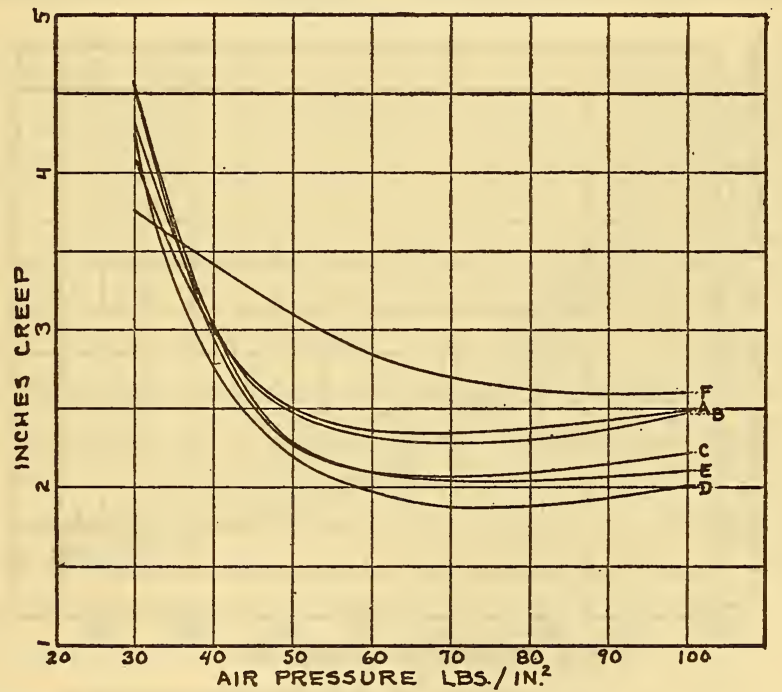

FIG. 13.-Influence of alterations in tread on creep shown as inches per tire revolution (see fig. 5).

${ }_{35} \times_{5}$ cord tire; speed, $25 \mathrm{mph}$; axle load, I,650 pounds; no tractive effort.

for the breaker and cushion construction. It will be seen that the differences in power loss show up very plainly, and, with tires otherwise the same, may be traced to a greater or less internal friction at a very definite portion of the tire.

These examples are pointed out in order to show that by progressive tests it is possible to closely trace just what takes place inside a tire and actually measure the effect of details of design.

\section{SIGNIFICANCE OF POWER LOSS DETERMINATION.}

\section{FUEL CONSUMPTION.}

The power required to supply the amount absorbed by the tires and dissipated as heat must come from the fuel used and accordingly a change in the kind of tires, or the conditions under which 
tires are run, will manifest itself in an increase or decrease in fuel economy. However, in order to properly evaluate the relative effect of the tires it is necessary to take into consideration several factors which enter into automobile operation in themselves subject to large variations. It is not within the scope of this paper to go into all these details, but from general conclusions and road tests, it is not out of the way to attribute a difference in fuel consumption of as much as Io to 20 per cent to changes in tires or tire conditions.

\section{HIGHER TEMPERATURES.}

Inasmuch as the energy absorbed by tires is dissipated as heat, a rise in the temperature results. Whether or not this temperature

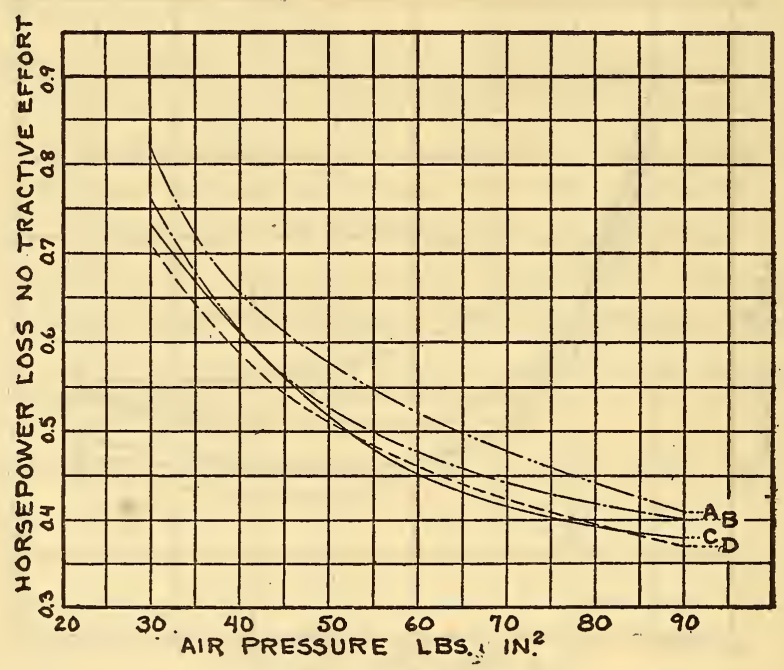

FIG. I4.-Influence of changes in design on power loss.

Four $32 \times_{4}$ cord tires; axle load, 885 pounds; speed, $25 \mathrm{mph}$.

is high enough to be seriously detrimental to the rubber will depend upon the design of the tire, how it is run, the kind of road, weather conditions, etc. If it is run at a high speed for a considerable length of time, the temperature maintained in the tire may have a considerable bearing on its life. It is impossible to give definitely the temperature equivalent of the power loss because there are so many other factors which enter, but if a tire is run at a speed of say 30 miles per hour for a considerable time, a temperature from I 25 to $200^{\circ} \mathrm{F}$. may be easily obtained, depending upon the tire.

For the average car, which is driven usually at lower speeds and frequently stopped, the temperature is probably not of great importance. In racing, particularly, and in touring it may have quite a deteriorating effect, and thus shorten the life of the tire. 


\section{UNIFORMITY OF PRODUCT.}

In making tests on tires of different sizes, or on different tires of the same size, made by a manufacturer, it has been noted that one manufacturer's product will show uniform or consistent results throughout, while another's gives quite varying results, some tires being unusually low and some unusually high in power loss.

It would appear that this latter condition results from lack of proper control through the manufacturing processes or else in inconsistencies in the design of the tires. If such is the case, dynamometer tests should be of immense value in locating and remedying such discrepancies.

\section{INTERIAL FRICTION.}

The ideal tire would be one which was perfectly elastic. The power loss would be zero, as the force used in compressing the tire as it approached the road would equal that exerted by the tire against the road as the compressed portion resumed its original shape. This ideal tire will probably never be built, but by referring to Figures 2, 3, and 4 it will be seen that, at least, some tires come much nearer to the ideal than others. By comparing the cord tires of to-day with the fabrics of a few years ago, it will be seen that considerable progress has been made in this direction, and the result is very evident from the greater life of the cord tire.

One way of looking at the power loss in a tire is that it is the hysterisis loss of the whole tire. Since this loss in the whole tire is made up of the sum of all the small losses throughout the tire, the problem is to reduce the loss in unit parts. A tire is made principally of a combination of rubber and cotton, the cotton giving strength and permanency of form while the rubber serves as a bond to hold the parts together. As the tire flexes, the cotton must still give the strength to the carcass, while at the same time the relative position of the individual fibers and cords change. One of the big problems in tire construction is to so build them that, as the positions of the fibers and cords change, the rubber bond will not be broken. Taking an imaginary unit section of rubber in a tire, there are two factors which should be observed in order that the power loss be low. The rubber compound must be of such a nature that the hysterisis loss is small and the unit strain on the rubber must be low.

Referring to Figure I5, these points are brought out by the four hysterisis curves. These are simply typical curves based on known properties of rubber compounds. A represents a condition 
of a large hysterisis loss due to the nature of the compound and a high strain. In $\mathrm{B}$ the loss is reduced by changing the nature of the compound. In $\mathrm{C}$ the loss is reduced using the $\mathrm{A}$ compound, but reducing the strain. The best condition is shown at $\mathrm{D}$, where the $\mathrm{B}$ compound is used and the strain is reduced. If the condition shown at $D$ is carried out throughout the tire, the hysterisis of the whole tire will be low; or, in other words, the internal friction, and hence the power loss will be low.
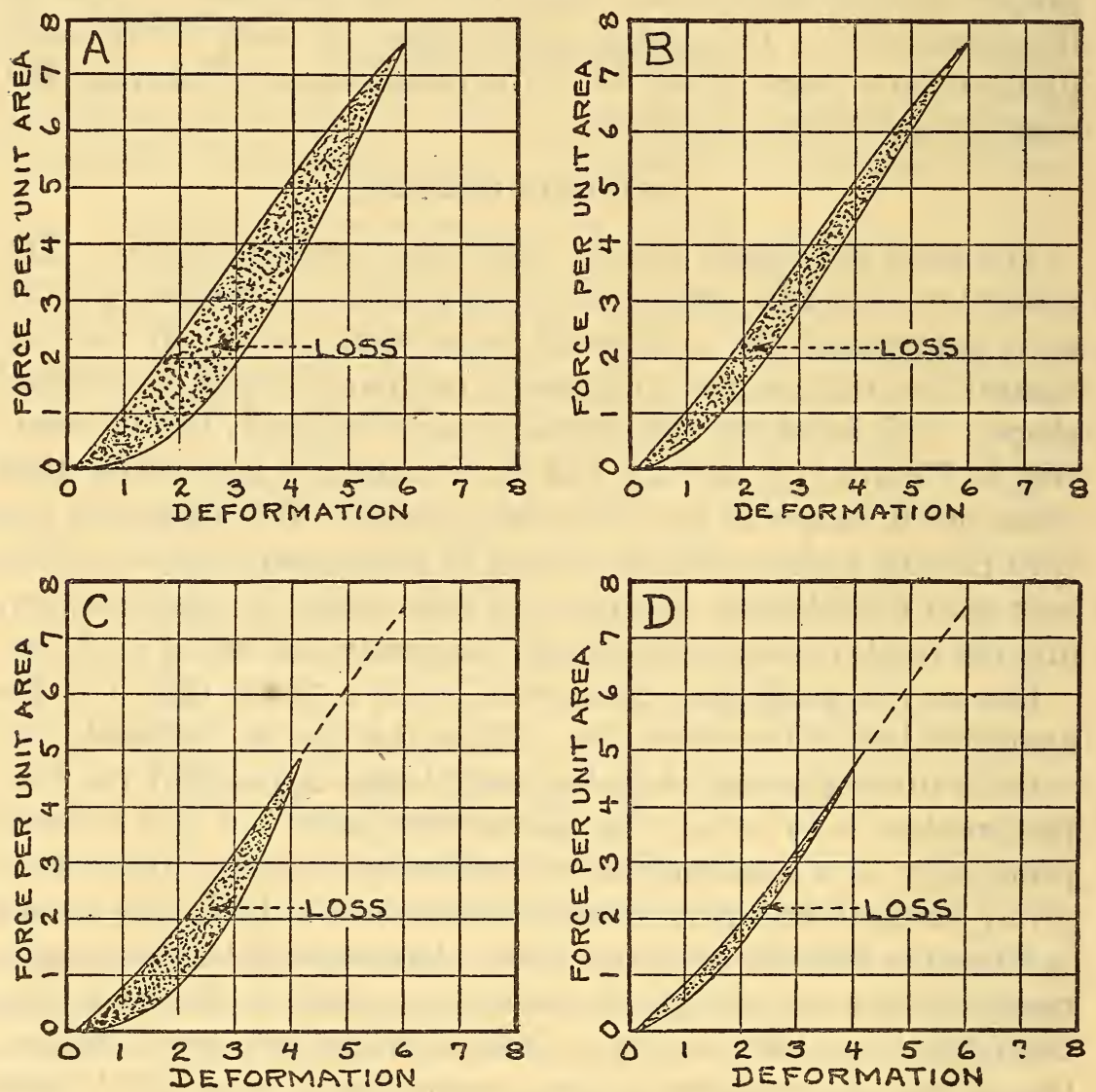

FIG. I5.-Typical hysterisis curves.

\section{CONCLUSIONS.}

The outstanding feature brought out by these dynamometer tests is the wide variation in the power loss of different makes of tires.

In tests which have been made during the past few years in particular, by Prof. E. H. Lockwood, of Yale University, the following conclusion was reached: In the average passenger car run- 
ning on a hard, level road at 20 miles per hour approximately onehalf of the power developed by the engine is used in overcoming the rolling resistance of the tires. Using this figure as a basis, it is seen from the data presented in this paper that a considerable difference in the fuel consumption of an automobile can be attributed to the choice of tires. The actual saving in dollars will depend upon the economy of the engine and will also vary with the conditions under which the automobile is operated. This subject will be treated fully in a later paper.

In addition to bringing out the differences with respect to power loss which exist among different tires, dynamometer tests should be of great value in the study of details of design of individual tires. It has been pointed out that most of the power loss in a tire occurs in the carcass and accordingly it is not surprising that there is a decided difference between the power loss in a cord and in a fabric tire. But taking either cord or fabric tires as a class where constructions are fundamentally the same, the lack of uniformity suggests an opportunity for profitable study. The use of dynamometer tests in making such studies is brought out by the results pointed out in Section III, 7. These show the possibility of extending the analysis of power losses much further and measuring the effect of the many small variables which enter into the construction of a tire. By means of such tests it should be possible to coordinate more closely the different parts of a tire for maximum efficiency.

Washington, February 9, I 923. 